\title{
DETERMINING THE PURPOSEFULNESS OF NEW SERVICES ON THE GROUNDS OF THE RESULTS OF QUANTITATIVE ANALYSIS
}

\author{
Rolandas Drejeris ${ }^{1}$, Juozas Bivainis ${ }^{2}$, Živilè Tunčikiené ${ }^{3}$, Eglẻ Drejerienė ${ }^{4}$ \\ 1, 2, 3 Department of Social Economics and Management, Vilnius Gediminas \\ Technical University, Sauletekio al. 11, LT-10223 Vilnius, Lithuania \\ ${ }^{4}$ Department of Obstetrics and Gynaecology, Lithuanian University of Health Sciences, \\ Medical Academy, A. Mickevičiaus g. 9, LT-44307 Kaunas, Lithuania \\ E-mails: ${ }^{1}$ rolandas.drejeris@vgtu.lt (corresponding author); ${ }^{2 j u o z a s . b i v a i n i s @ v g t u . l t ; ~}$

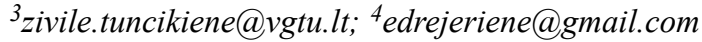

Received 08 November 2012; accepted 31 January 2013

\begin{abstract}
The goal of the present article is to propose a methodology for substantiating the purposefulness of new service development reasoned by the results of a quantitative analysis of the current situation. The core of determining the purposefulness of new service development is assessing and comparing two trends of service business development: new service implementation and the main alternative of this process - the expansion of the scope of the current services. The paper demonstrates how the authors consolidate, annotate and critique available research on some logical aspects of new service development in order to find more objective quantitative decisions. The study provides the methodology (process model) of determining the purposefulness of new service development. A new attitude is evidenced by discovering quantitative assessment according to different sets of criteria. The paper also improves the comprehension of the complex process of new service implementation - proves the necessity of the first step, i.e. the determination of the purposefulness of a new service, which is often missed by authors. Appropriate solutions, according to the results of the suggested quantitative analysis, would increase the objectivity of assessment and the probability of successful new services.
\end{abstract}

Keywords: service business, purposefulness, new service, development, process model, quantitative analysis.

Reference to this paper should be made as follows: Drejeris, R.; Bivainis, J.; Tunčikienè, Ž.; Drejerienè, E. 2013. Determining the purposefulness of new services on the grounds of the results of quantitative analysis, Journal of Business Economics and Management 14(4): 791-805.

JEL Classification: C13, C52, G20, L89, M11, O31.

\section{Introduction}

Contemporary competition in the field of services encourages firms to look for new ways and methods of development in order to achieve better satisfaction of growing customer needs and improve business results. The main subject is what area of growing companies has to be taken so that to achieve better customer allegiance, to retain 
or improve the image of the company and to have profitable results of development.

Service companies develop new products, penetrate into new markets and expand the scope of the existing activities with the aim to reach their objectives. Firms can take a chance to choose many courses of development. However, which one is the best to support such understanding and what time is the most useful for starting the development of a new service? These are the questions relevant to every service company. Thus, it is unquestioned demand for a focus on determining the purposefulness of new service development and comparing it with other courses on development.

To investigate the failures of implementing a new product, the majority of researchers state that inadequate planning and insufficient analysis of implementation are among the possible reasons of a new tangible product or service failure. One of the possible reasons for new product failure, as mentioned above, might be the failure or ineptitude of substantiation or an inadequate substantiation of the purposefulness of new product development. Salavou (2004) generalizes that a lack of knowledge about the purposefulness of developing innovations can be one of the reasons for their failure. In order to produce and successfully commercialize a new service, firms must synthesize a wide variety of expertise and knowledge that is usually very different. Such circumstances challenge different results of implementation as often as they are unsuccessful and unmarketable.

The above mentioned situation encouraged finding an objective solution regarding the purposefulness of new service development with the application of a more unprejudiced quantitative methodology. A quantitative assessment of the situation is more objective in this case and can more precisely express the needs of a modern and global market (Kaplan 2004). Businesses have not an objective methodology for determining the purposefulness of innovations addressed to a service sector; an available basis of knowledge of these issues is very small and consists though of minor fragments or experimentation but without the allied analogy. Considering a variety of practical situations, an all-rounded flexible methodology adapted for different service business conditions is needed (Stevens, Dimitriadis 2005; Bivainis, Drejeris 2006). Thus, the overall absence of a particular scientific solution to developing the purposefulness of quantitative determination is considered to be a problem of the article. The aim of the paper is to present the process model substantiating the purposefulness of developing new services that would be created on the basis of the conclusions of scientific literature and the application of systematic and logical analysis as well as adapted for the service sector.

\section{Process model of determining the purposefulness of new service development}

The determination of purposefulness means the first step of a new service development process. Bivainis, Drejeris (2006) have mentioned that such step is necessary for better readiness, and using the results of assessment procedures is one of the conditions for the avoidance of new service failure. The failures of new services show the importance of this phase. 
Scientific literature presents information on many exponents stating the necessity of determining the purposefulness of new service development; nevertheless, most of them only discuss the significance of the process and do not suggest any methodology for assessing. Avlonitis et al. (2001), Baker, Hart (2008) and many other researches, who focussed on new product development, take the substantiation of purposefulness for granted and do not find it is sufficiently considered stating it is always worth developing a new product and providing the description of positive results followed by any innovations implemented in company's activity.

Scientific and special literature suggests only a few cases considering the purposefulness of some process or product. Bivainis, Drejeris (2008) tried to find a few solutions to determining the purposefulness of new services, but their research was not finished and was not clear enough to business practitioners. Bivainis, Tamošiūnas (2003) suggested a relevant methodology based on quantitative computation for determining the purposefulness of restructuring companies. Cozijnsen et al. (2000) presented an original method for assessing new product requirements based on the conformance to the company's objectives. Amara et al. (2004) proposed research results introducing the determination of innovativeness and solutions to manufacturing product innovation.

The purposefulness of some medical actions is reasoned quite frequently in medical literature. A study on the management of psychological human resources often uses the term "purposefulness" as the fourth super-factor for describing individual differences that influence personal innovativeness (Dyck 1994; Yun et al. 2007). Filippetti (2011) reviewed the process of creating many innovation modes according to different procedural factors, the size of a company, sectors, reasons for failure, but neither of them found requirements for presenting information about the methodology for determining purposefulness, though knowledge of this process was mentioned as one of the main factors in success.

It is obvious that the direction for any trend towards business development has conformity to the company's objectives and its realization better meets the growing needs of customers (Santouridis, Trivellas 2010). The existing product can be quite successful, and therefore it is not necessary to promptly invest in the process of implementing innovations. The assessment of the rate of market growth and market share can determine such situation.

Environmental factors have to be also assessed, because the direction of business development cannot contradict their requirements (Forsman 2008). In the majority of cases, the development of innovations presses for investment (Walters 2004), i.e. the assessment of investment efficiency and risk assessment have to be important components in the model for determining new service purposefulness.

A lack of innovation potential can disturb a successful process of new service implementation (Grieco 2006). Thus, the innovation potential for the company has to be also assessed. Resolving the degree of the novelty of a new service is a relevant question for the companies getting a positive result of its implementation (Grieco 2006).

Considering the requirements for new service development and according to the results of practical research, the model consisting of seven serialized components is proposed 
(Fig. 1). Every selected component of the suggested model destines some respective assessment particularly important to developing the process and having an influence on the occurring business events of the company under contemporary conditions. Requirements for the above mentioned components and their content are presented in the following sections.

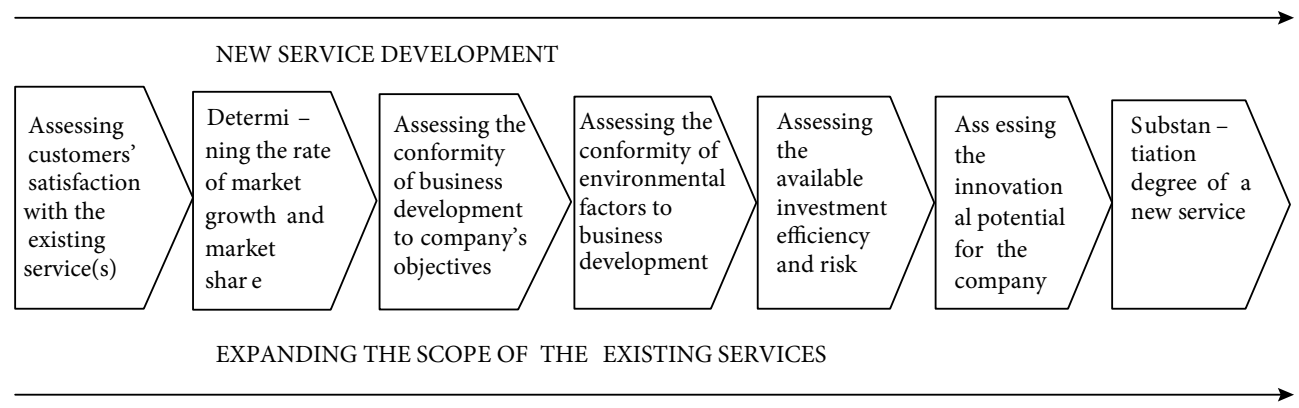

Fig. 1. Process model for determining the purposefulness of new service development

The use of the methodology forecasts the possibilities of evaluating both business development directions: new service development and an increase in the scope of the existing services. The model emerges the possibilities of narrowing time for investigation down and reducing unproductive expenditure. Even though James, O. et al. (2000), Avlonitis et al. (2001) and a few more authors suggest more business development directions (business development in different markets using other business technologies and different marketing instrumentalities), in this case, they agree that implementing new services and expanding the scope of the existing ones are the main directions for developing service companies and therefore are preferred to being analyzed. Though the suggested methodology is appropriate to assessing other mentioned directs, the findings of the article are more concentrated on determining suitability for the situation starting the implementation of new services.

Following the carried out assessment based on the first six components of the model, eventually, the following decisions can be made:

1) the development of any new activities should not be pursued;

2) the development of a new service should be pursued;

3) the scope of the existing services should be increased;

4) the development of a new service should be pursued and simultaneously the scope of the existing services should be increased.

The designed model (Fig. 1) suggests the consistency to be followed with respect to the evaluation of the purposefulness of both business development trends in parallel with the established criteria and using the given methods. The direction in business development is considered to be purposeful only in case it is positively evaluated by all criteria encapsulated in the components of the model, because each aspect, the evaluation of which is recommended in the components of the model, is regarded as significant enough for service business. The direction of development that failed to comply with 
at least one value of the proposed criteria of the models will be regarded as inappropriate. In two cases determining it is purposeful to develop a new service or to increase a growth in the scope of the existing services, it is necessary to extend investigation into the seventh component that explains reasoning behind the novelty of the service. The structure of the proposed model allows suspending assessment when taking any direction for development does not fully satisfy one requirement scheduled in the components of the model.

The suggested model is appropriate and fitted for the service sector because of better flexibility of the product and a better possibility of adjusting to contemporary changeable environmental factors. The sequence of the components is fitted for the service sector, and, after testing a few service companies, was proved out. Furthermore, some assessments provided in the suggested components of the model can be applied for service companies only.

A consistent evaluation of the purposefulness of both business development trends by stages provides a possibility of identifying unpromising efforts (trends towards development) at each stage of research, cancelling such efforts and constricting research thus reducing non-productive costs and time for preparing the implementation of a new service. It is an important presumption, because time for marketing has become a key competitive element (Gremyr et al. 2010; Jimenez-Zarco et al. 2011). The suggested construction of the proposed model and quantitative evaluations encapsulated in the components of the model create preconditions for transposing these evaluations in the medium of modern information technologies.

\subsection{Assessment of customer satisfaction}

Conditions for business service development, on one hand, are closely related to the possibility of improving the satisfaction of customer needs and requirements (for example, in relation to price and quality). On the other hand, they are linked to customer readiness to pay for the service a certain amount that would be also appropriate for the service company. The satisfaction of service customers and the effective use of company expenditures, in most of cases, are understood as the main business development conditions predetermining the necessity to assess the desirability of the existing services provided at service companies. It is one of the most important criteria that allow making a decision regarding the directions of service company activities that are worth pursuing, have to be improved and can be refused.

Capelia and Turner (2004) have offered a questionnaire for measuring the degree of customer satisfaction where the majority of criteria are of a qualitative character. Similarly, the method is suggested by Santouridis and Trivellas (2010) and Jiang, Wang (2006) stating that customer satisfaction can be measured and evaluated by either a single-item scale or as a multi-item construct assessing the satisfaction of each component of the service. However, for improving the objectivity of computation, changing some criteria into the quantitative ones and imposing constraint upon the set of criteria can be suggested: not less than a half of them have to be quantitative. According to the results of the customer survey, the satisfaction degree of the current services might be computed in the following way: 


$$
G_{e}=\sum_{j=1}^{n} W_{e j} \eta_{j}
$$

where: $W_{e j}$ - the value of assessing criterion $j$ of the current service $e ; \eta_{j}-$ the significance of criterion $j$. The above mentioned Capelia and Turner (2004) propose a scoring method and assessment of customer answers within the interval [2 (absolutely agree); -2 (absolutely disagree)]. This is a simplified assessment of criteria importance by giving them weight from limited selection 2, 1 and 0 . Based on the values of a cumulative criterion, it is possible to rank services according to customer satisfaction. Thus, the above mentioned methodology can be really used for assessing the degree of customer satisfaction.

\subsection{Determining the rate of market growth and market share}

The implementation of a new service can be a critically important competitive factor in service industry. A greater market share, in turn, reduces the likelihood of business dissolution while introducing important new services providing little or no reduction in the likelihood of business dissolution net of the market share effects that the firm achieved. Thus, it is necessary to determine a situation looking at the current services provided at the company. It is recommended to determine the marginal value of the cumulative criterion below which the values of the criteria have to be treated as confirming customer dissatisfaction regarding provided services. In order to provide a comprehensive assessment of market possibilities, it is worth determining the rate of market growth of the company and the market share during the last five years according to classical formulas, when providing the current certain services.

The summary of the conducted assessment based on the above mentioned two first components of the suggested model is described below:

1) Following the analysis of the services that do not satisfy customer needs and following determination that market growth in the current services is not sufficient while the market share of the company is decreasing, the only decision is possible - it is not worth increasing the scope of such services for a company and continuing research on the purposefulness of new service implementation while rejecting the idea of expanding the scope of the presently provided (current) services.

2) When the assessment confirms a growth in services satisfying customer needs or a growth in the company's market share, the conclusion provides that the customer needs the service, provision for the service has to be improved, research on the reasons for customer dissatisfaction has to be continued and the reasons have to be detected. The disclosed reasons have to be eliminated for gaining a competitive advantage.

3) When the provided services meet customer demands, the rate of market growth is evident, the company's market share grows and it is worth continuing research on the feasibility of both development directions based on other components of the suggested model. 
Salavou (2004) and Trot (2001) state that the result showing that concept of some business trend development corresponds to market requirements and substantially increases the probability of the commercial success of a new product. Incidentally, it is meaningful to accept the proposition of the researchers that the analysis of market requirements is necessary at most stages of new product development. It means that such analysis is also necessity for determining the purposefulness of new service development.

\subsection{Conformity of business development to the objectives of the company}

Quite a few researches consider the conformity of business development to company's objectives as the most important factor in determining the purposefulness of new service development. The majority of them find the necessity for satisfying customer needs as one of the objectives of innovations stimulated by the company. Chaitanya (2005) analysed financial services, and one of the conclusions argues that the main objective of the analysed financial services provided by the company is to improve the satisfaction of customer needs. The research results confirmed that implementing a new financial service was purposeful. Forsman (2008) shows a framework of success dimensions as an objective of every company, but, unfortunately, they are not quantitative. Cozijnsen et al. (2000) presented a list of company's objectives, and the most of them are for better effectiveness and for improving the quality of services. It would be better to add more specific objectives the importance of which for the service company is argued by Mohanty (1999):

1) shortening the term of service provision;

2) increasing service package.

Only Cozijnsen et al. (2000) suggest an application of a relative indicator for assessing new product success and for selecting the most feasible product or service. Undoubtedly, such assessment would be useful for the validation of purposefulness regarding directions for the development of a service company. The relative indicator $(X)$ of reaching objectives is calculated as follows

$$
X=\frac{\sum_{i=1}^{n} T_{i} \eta_{i}}{\sum_{i=1}^{n} T_{i}},
$$

where $i$ is an objective index; $T_{i}$ - assessment indicating the attainment of the objective (following new service implementation or an increase in the scope of the existing services); $\eta_{i}-$ the significance of the objectives.

The following assessment indicators for determining the attainment of objectives can be suggested: 2 - certainly positive impact on reaching company's objectives, 1 - probably positive impact on reaching company's objectives, 0 - business development will have no impact on company's objectives, -1 - probably negative impact on company's objectives, -2 - certainly negative impact on company's objectives.

The computed values of indicator $X$ allow making a decision as to which an alternative for company's development better meets company's objectives $\left(X_{n}-\right.$ new service 
development, $X_{s}$ - increase in the scope of the existing services). When $X_{n} \triangleright X_{s}$, the implementation of new services better corresponds to company's objectives, and therefore it is purposeful to implement new services; when $X_{n} \triangleleft X_{s}$, it is purposeful to increase the scope of new services. The following comparison of values $X_{n} \cong X_{s}$ is also possible. In this case, it is worth continuing research on the purposefulness of both business development directions.

It is worth sighting that a formal application of a relative indicator for reaching objectives may provoke the rejection of excellent ideas as not meeting company's objectives. In order to obviate, it is also worth having a periodical revision of company's objectives and assessing adequacy for changes in the recent business situation. Promoting profitable and sustainable business activity that meets customer requirements and expectations and remaining ahead of competitors always recognize and maximize the opportunities of activity.

\subsection{Assessment of environmental factors influencing business development}

Environmental factors that affect the selection of a direction for business development may involve an economic state of the country (region), for example, inflation rate, unemployment rate, currency exchange rate, the attitude of society such as toleranceintolerance, encouragement, government policy, cultural, political environment, etc. Such assessment would allow determining whether certain business development alternatives do not go into conflict with environmental requirements in the related market. Moreover, such assessment demonstrates that business development alternatives are either purposeful or not in certain markets. Therefore, the matrix determining the influence of environmental factors (Table 1) on the favourability of the markets developing alternatives for service business can be suggested.

The nature and composition of the impact depends on the character of services and the scope of company's activities. Therefore, it may be different for the companies that provide different services. The nature and strength of the influence could be expressed within the following interval: -1 certainly negative impact on business development in that market, +1 the most favourable environment for business development in that market.

Table 1. Matrix for determining the influence of environmental factors on both directions of business development

\begin{tabular}{lllllll}
\hline \multirow{2}{*}{$\begin{array}{l}\text { Factors having an impact } \\
\text { on service development }\end{array}$} & Market A & \multicolumn{2}{l}{ Market B } & ......Market $n$ and etc. \\
\cline { 2 - 6 } & NSD & DSCS & NSD & DSCS & NSD & DSCS \\
\hline 1. & & & & & & \\
\hline 2. & & & & & \\
\hline$n . \ldots . .$. and etc & & & & & & \\
\hline
\end{tabular}

In total:

Notes: NSD - new service development, DSCS - development of the scope of the current services. 
The aggregate columns of the matrix allow making a decision as to which business development direction is more suitable for a certain market. The cases, when the market is favourable for all above mentioned business development alternatives may be also accepted. In such situation, every business development alternatives should be assessed further by the criterion for assessing investment efficiency and risk. Thus, the present assessment will help in choosing even the best market for business development.

\subsection{Assessment of investment efficiency and risk}

Both directions of business development (developing a new service or expanding the scope of the existing services) have to be compared in terms of investment efficiency, and the decision has to be taken to develop activity having better efficiency of investments. Unfortunately, the problem arises due to economic indicators of new services that are highly indeterminate. Considering such situation, starting the assessment of the rate of forecasted investment efficiency, regarding the growth of recent services only, can be suggested, then following the assessment of probabilities of new service development in case of equal investments. It is worth judging the possibilities of applying for the experts. Nevertheless, it is also important to highlight that new services have to better meet customer requirements (Chaitanya 2005).

Customers will accept a new service when it meets one of the following requirements (Se-Joon Hong et al. 2006):

1) utility;

2) pleasure / satisfaction;

3) accessible price;

4) exclusive use;

5) simplicity / comprehensibility.

Company managers and experts have to decide if particular investment (calculated for the growth of provided current services) is sufficient for the development and implementation of a new service that would meet one of the conditions mentioned above, have better efficiency of investment, conform to the customer's decision to buy stuff for the price and satisfy company's requirements. The date for such investigation can be set taking into consideration similar projects.

The reached conclusion would be a preliminary decision on selecting business direction and the feasibility of new service development. If conclusions demonstrated that potential investments were insufficient for new service implementation, the company would have to dispose such idea and continue investigation into a growth in the scope of the current services. If the conclusion made by an expert states that investment is sufficient for new service development, there is a need to continue investigation according to other components of the suggested model.

Thus, what investment efficiency indicators can be used? Which comparison of indicators would enable the validation of a choice to develop a new service or to grow the scope of recent services? The authors of different papers have a varying opinion regarding this issue. Ross (2002), Pogue (2004), Park and Choi (2011) suggest using these in- 
dicators to determine the efficiency of investment in business projects: net current value, the period of return on investment, the index of profitability and the rate of investment efficiency. Other authors (Mohanty 1999; Walters 2004; Mackevičius 2005), besides earlier mentioned information, suggest using return on investment indicator. Walters (2004) investigated the variants of the company's strategy for business development and stated that any alternative of selecting strategic activity had to be reasoned by the assessment of return on investment.

It has to be noted that Walters (2004) suggests qualitative indicators for computing return on investment. Therefore, such assessment reduces the objectivity of the performed assessment. Mackevičius (2005), in his monograph, accepts an indicator for return on investment, which helps in comparing potential profit and investments into business development. Hence, it can be assented to using a classical formula calculating return on investment comprising of proportion average profit per year and investment into business development.

The managers of the companies always seek for profit. Consequently, it is important to assess business risk, know its range and do not keep on the edge. In conclusions of his monograph, Mackevičius (2005) states there is no activity that is not related to particular risk, but in some circumstances, risky decisions can become much more useful than the cases without any risk.

Ahmed et al. (2007), Sanchez et al. (2009) and other researchers support the opinion of evaluating investment projects. They determine the risk of the project as the probability of the project results deviating from the expected results. Sow-Lin Chan at al. (1992) and other researchers recommend using a decision tree method and simulated model for comparing two or more investment projects. These methods are useful for determining the best investment solution to the company. Verbano, Nosella (2010) described many methods that allow making a decision whether investment projects should be undertaken, continued or killed. They prefer quantitative methods and state that using them depends on an economical situation. Mackevičius (2005) expresses the risk in relation to alert and protection factors:

$$
R=\frac{f(P)}{f(A)},
$$

where $P$ - degree of alert; $A$ - plenty of protection factors.

Thus, it means that increasing the degree of alertness expresses the probability of increasing the risk. Mackevičius (2005), Walters (2004) suggest calculating risk rate for quantitative risk assessment:

$$
r=\frac{L_{p}}{K_{o}},
$$

where $L_{p}$ - possible supreme loosing; $K_{o}$ - own capital.

Mackevičius (2005) discusses a wide spectrum of relationships between business development and company's profit. He argues it is a miserable chance of getting large profit and low risk and warns that high risk may involve more losses. 
Williams et al. (2003), Verbano and Nosella (2010) and many other researchers suggest assessing risk to dispose it for the experts. They have to estimate the factors predetermining the risk of business development, positive and negative characteristics of all business development directions, return on investment of every case, predicting possible losses and offering tools for reducing the risk. This information helps in making a decision.

\subsection{Assessing the innovation potential of companies}

Analyzing the innovation potential has to be prosecuted by taking both business development alternatives separately thus assessing the possibilities of implementing new services and expanding the scope of the current services if both alternatives has been assessed as corresponding to the criteria of development by previous assessments. Therefore, which development direction has a better potential that can be determined only after measuring the innovation potential for the company according to the possibilities of both above mentioned directions for growth. Grieco (2006) states that maintaining sufficient innovation potential seems to be one of the reasons for successful company's development. The innovation potential for the company can be measured by technicaltechnological potential and personnel creativity (Grieco 2006). Mackevičius (2005) presented several indicators for assessing the technical-technological potential for the companies; however, not all of those can be used for determining the technical-technological potential for the service company. Only the rate of effective methods for processes can be suitable for the service sector. Thus, $M$ is the rate of effective methods for processes and is appropriate for determining the technical-technological potential for the service:

$$
M=\frac{V_{g}}{V_{v}},
$$

where $V_{g}$ - gauge of effectively provided services; $V_{v}$ - gauge of provided services at a particular time.

Particularly expedient information about the decision on business development direction would be a dynamic analysis of effective ways of service rates, including a comparative analysis of market share and market growth dynamics. Changes in the function rates can facilitate the diagnosis of the following decisions:

1) Technical-technological potential is unfulfilled, services are provided using ineffective methods because of a lack of modern equipment or shortage of skilled employees; in order to provide services more efficiently, it is economically feasible to acquire better (more modern) equipment for providing services or to recruit better (higher qualified) employees;

2) Demand for services decline because of falling into desuetude, i.e. requirements for changing technology or rejection of providing the current services; it is worth analyzing the possibilities of implementing a new service;

3) Demand is growing, technical possibilities are sufficient, and therefore it is worth analyzing the possibilities implementing a new service and extending the scope of the current services. 
Following the above mentioned assessments, a decision about a direction for the further development and purposefulness of new service implementation can be made.

\subsection{Substantiation degree of the novelty of a new service}

Following the decision in favour of developing a new service, a question about the degree of its novelty arises. Amara et. al. (2004) found it the most important decision when a company had concluded to develop a new producible item. Beyond doubt, such proposition also obtains a new service. The before mentioned authors call the degree of novelty as a radical degree and propose the findings of investigations regarding innovations in traditional manufacturing industries. According to their findings, the following factors influence the degree of novelty in manufacturing industry:

1) the amount of finance intended for a process of making a new product;

2) creative potential for available employees;

3) a possibility of getting raw materials for making a new product;

4) technical-technological potential for the company;

5) possession of necessary information about a business network.

It is evident that the analysis of the above mentioned factors is necessary for determining not only the novelty of the producible item but also a new service. Salavou (2004) described three levels of product (service) novelty: the product (service) can be novel for customers, for a company and for customers and the company at the same time. Thus, novelty needs to be assessed according to the possibilities mentioned above. Amara et. al. (2004), Salavou (2004) suggest the assessment of novelty to be disposed to the experts of the companies.

Besides, the argumentation of expert decisions needs to complement consistent patterns established by Grieco (2006) who determined future innovations regarding various degrees of novelty:

1) The probability of success for implementing innovation is higher when innovation is less of novelty comparing with high-novelty innovation;

2) The immediate impact of percentage on profits after implementing innovation is assumed to be lower in case of less modern innovations as compared to the highly modern ones;

3) The presumable premium of less modern innovations is lower than that of highly modern innovations;

4) While highly modern innovation determines a steady rise in the profit trend equal to the percentage of the previous profit level, less modern innovation produces an instantaneous rise in the profits of a percentage that is followed by a gradual decline, but only as far as the level that is higher than the initial level.

It should be noted to Jiang, Wang (2006) who admonish that companies have to assess their possibilities of providing a new service of high quality only, because good quality is the guarantee of success, and these possibilities can help in making a decision what level of the novelty of a new service is the best. Hence, service companies have to asses every mentioned factor before making a decision about service novelty, because this decision is responsible and important for future results. 


\section{Conclusions}

A competitive advantage in market economy can be achieved by finding ways to realize company's opportunities to better satisfy customer needs. Researches make contradiction points for the purposefulness of developing a new product (service). This article proves it is not only useful but also very important for service companies to substantiate the purposefulness of developing a product prior to implementing new services in order to reduce the failure probability of novelty. In search of prospective solutions, both business development directions (implementation of new and increasing the scope of the existing services) have to be analysed in order to determine their purposefulness.

The article presents the model made of seven components and appropriate for the substantiation of the purposefulness of new service development. The model allows a complex assessment of a wide spectrum of actions determining the purposefulness of different business development alternatives in order to compare them and making the most objective solutions defining a proper time for starting the implementation of a new service.

Each component of the model has to be purposefully assessed considering the application of different quantitative methods that allow reducing the aspect of coincidence and have a rather objective assessment of each business development alternative.

The model of purposefulness presented in this article combines the results of our exploratory research on new service development and can be used for establishing a systematic framework for better new service management. Using the proposed methodology will help service companies in developing new services more effectively because of the growing possibility of reducing the probability of failure and decreasing time for implementing a new service. The construction of the model allows cutting down assessment expenditure and time necessary for implementing a new service.

\section{References}

Ahmed, A.; Kayis, B.; Amomsawadwatana, S. 2007. A review of techniques for risk management in projects, Benchmarking: an International Journal 14(1): 22-36.

Amara, N.; Landry, R.; Becheikh, N.; Ouimet, M. 2004. Radical innovations in traditional manufacturing industries, in Druid Summer Conference "Industrial Dynamics, Innovation and Development 2004”, June 14-16, 2004, Elsinore, Denmark.

Avlonitis, J. G.; Papastathopoulou, P. G.; Gounaris, S. P. 2001. An empirically-based typology of product innovativeness for new financial services: success and failure scenarios, Journal of Product Innovation Management 18(5): 324-342. http://dx.doi.org/10.1016/S0737-6782(01)00102-3

Baker, M.; Hart, S. 2008. The Marketing book. Sixth edition. London: Butterworth-Heinemann.

Bivainis, J.; Drejeris, R. 2006. Improvement of the pattern of new service development, Business: Theory and Practice 1: 14-21.

Bivainis, J.; Drejeris, R. 2008. Complex assessment of new service development, in Conference "Business and Management 2008”, April 14-16, 2008, Vilnius, Lithuania.

Bivainis, J.; Tamošiūnas, A. 2003. Enterprise restructuring programmes: evaluation and implementation, Management of Organizations: Systematic Research 27: 17-33. 
Capelia, F.; Turner, T. 2004. Development of an instrument to measure consumer satisfaction in vocational rehabilitation, Rehabilitation Counseling Bulletin RCB 47(2): 76-85.

http://dx.doi.org/10.1177/00343552030470020201

Chaitanya, K. 2005. Metamorphosis of marketing financial services in India, Journal of Services Research 5(1): 155-171.

Cozijnsen, A. J.; Vrakking, W. J.; Ijzerbo, M. 2000. Success and failure of 50 innovation projects in Dutch companies, European Journal of Innovation Management 3(3): 150-159.

http://dx.doi.org/10.1108/14601060010322301

Dyck, M. J. 1994. What does proposed purposefulness superfactor really describe?, Personality and Individual Differences 16(3): 411-415. http://dx.doi.org/10.1016/0191-8869(94)90067-1

Filippetti, A. 2011. Innovation modes and design as a source of innovation: a firm-level analysis, European Journal of Innovation Management 14(1): 5-26.

http://dx.doi.org/10.1108/14601061111104670

Forsman, H. 2008. Business development success in SMEs: a case study approach, Journal of Small Business and Enterprise Development 15(3): 606-622.

http://dx.doi.org/10.1108/14626000810892382

Gremyr, I.; Lofberg, N.; Witell, L. 2010. Service innovations in manufacturing firms, Managing Service Quality 20(2): 161-175. http://dx.doi.org/10.1108/09604521011027589

Grieco, D. 2006. Degree of innovativeness and market structure: a model, in Druid Summer Conference 2006 "Knowledge, Innovation and Competitiveness: Dynamic of Firms, Networks, Regions and Institutions", 18-20 June, 2006, Copenhagen, Denmark.

James, O.; James, C.; Rofee, I. 2000. The Evaluation of goal and goal-free training innovation, Journal of European Industrial Training 24(1): 12-20. http://dx.doi.org/10.1108/03090590010308228

Jiang, Y.; Wang, C. L. 2006. The impact of affect on service quality and satisfaction: the moderation of service contexts, Journal of Service Marketing 20(4): 211-218.

http://dx.doi.org/10.1108/08876040610674562

Jimenez-Zarco, A. I.; Martineiz-Ruiz, M. P.; Izguirdo-Yusta, A. 2011. The impact of market orientation dimensions on client cooperation in the development of new service innovations, European Journal of Marketing 45(1/2): 43-67. http://dx.doi.org/10.1108/03090561111095595

Kaplan, D. 2004. The sage handbook of quantitative methodology for the social sciences. London: Sage publication.

Mackevičius, J. 2005. Analysis of company activity: compilation, filing and assessment of information: Monograph. Vilnius: TEV.

Mohanty, R. P. 1999. Value innovation perspective in Indian organizations, Participation and Empowerment: an International Journal 7(4): 88-103. http://dx.doi.org/10.1108/14634449910283561

Park, J.; Choi, B. P. 2011. Interest rate sensitivity of US property/liability insurer stock returns, Managerial Finance 37(2): 134-150. http://dx.doi.org/10.1108/03074351111103677

Pogue, M. 2004. Investment appraisal: a new approach, Managerial Auditing Journal 19(4): 565-570. http://dx.doi.org/10.1108/02686900410530565

Ross, A. 2002. A multi-dimentional empirical exploration of technology investment, coordination and Firm Performance, International Journal of Physical Distribution \& Logistics Management 32(7): 591-609. http://dx.doi.org/10.1108/09600030210442603

Salavou, H. 2004. The concept of innovativeness: should we need to focus?, European Journal of Innovation Management 7(1): 33-44. http://dx.doi.org/10.1108/14601060410515628

Sanchez, H.; Robert, B.; Bourgault, M.; Pellerin, R. 2009. Risk management applied to projects programs, and portfolios, International Journal of Managing Projects in Business 2(1): 14-35. http://dx.doi.org/10.1108/17538370910930491 
Santouridis, I.; Trivellas, P. 2010. Investigating the impact of service quality and customer satisfaction on customer loyalty in mobile telephony in Greece, The TQM Journal 22(3): 330-343. http://dx.doi.org/10.1108/17542731011035550

Se-Joon Hong; Kar Yan Tam; Jinwoo Kim. 2006. Mobile data service fuels the desire uniqueness, Communication of ACM 49(9): 89-95. http://dx.doi.org/10.1145/1151030.1151034

Sow-Lin Chan; Hian-Chye Koh; Chan-Kee Low. 1992. Making auditing decisions: the Bayesian decision-tree approach, Managerial Auditing Journal 7(1): 24-31.

http://dx.doi.org/10.1108/EUM0000000001774

Stevens, E.; Dimitriadis, S. 2005. Managing the new service development process: tovards a sistemic model, European Journal of Marketing 39(1/2): 175-198.

http://dx.doi.org/10.1108/03090560510572070

Trot, P. 2001. The role of market research in the development of discontinuous new products, European Journal of Innovation Management 4(3): 117-125.

http://dx.doi.org/10.1108/14601060110390585

Verbano, C.; Nossella, A. 2010. Addressing R\&D investmen decisions: a cross analysis of R\&D project selection, European Journal of Innovation Management 13(3): 440-460.

http://dx.doi.org/10.1108/14601061011060166

Walters, D. A. 2004. Business model for the new economy, International Journal of Physical Distribution \& Logistics Management 34(3/4): 346-357. http://dx.doi.org/10.1108/09600030410533637

Williams, S.; Zainuba, M.; Jackson, R. 2003. Affective influences on risk perceptions and risk intention, Journal of Managerial Psychology 18(2): 126-137.

http://dx.doi.org/10.1108/02683940310465027

Yun, S.; Takeuchi, R.; Liu, W. 2007. Employee self-enhancement motives and job performance behaviors: investigating the moderating effects of employee role ambiguity and managerial perceptions of employee commitment, Journal of Applied Psychology 92(3): 745-756.

http://dx.doi.org/10.1037/0021-9010.92.3.745

Rolandas DREJERIS. Doctor of Social Sciences, Associate Professor at the Department of Social Economics and Management, Vilnius Gediminas Technical University. Research interests: innovation management, process of services development, theories of development, strategy for designing a new product, sustainable processes.

Juozas BIVAINIS. Doctor Habil, Professor at the Department of Social Economics and Management, Vilnius Gediminas Technical University. The author of over 240 scientific works. Research interests: intensification of economic development, business management theory, economic legislation.

Živilė TUNČIKIENĖ. Doctor of Social Sciences, Associate Professor at the Department of Social Economics and Management, Vilnius Gediminas Technical University. Research interests: management of social economic development, strategic management of public institutions, innovations in public services.

Eglė DREJERIENĖ. Doctor of Biomedical Sciences, lecturer at the Department of Obstetrics and Gynaecology, Medical Academy, Lithuanian University of Health Sciences. Research interests: developing innovations in medical services, new methods of infertility healing, innovations in gynaecology, implementation of new methods in surgery. 